\title{
Potentially Inappropriate Medication Prescribing Detected by Computer Algorithm among Older Patients: Results from the MAPT Study
}

\author{
Arnaud Pagès $1,2,3, * \mathbb{C}$, Laure Rouch ${ }^{1,2,3}$, Nadège Costa ${ }^{3,4}$, Philippe Cestac ${ }^{1,3}$, Philipe De Souto Barreto ${ }^{2,3}$, \\ Yves Rolland ${ }^{2,3}$, Bruno Vellas ${ }^{2,3}$, Laurent Molinier ${ }^{3,4}$, Blandine Juillard-Condat ${ }^{1,3}$ and MAPT/DSA Group ${ }^{\dagger}$ \\ 1 Department of Pharmacy, Toulouse University Hospital, 31000 Toulouse, France; \\ rouch.1@chu-toulouse.fr (L.R.); cestac.p@chu-toulouse.fr (P.C.); juillard-condat.b@chu-toulouse.fr (B.J.-C.) \\ 2 Institute of Aging, Gérontopôle, INSPIRE Project, Toulouse University Hospital, 31000 Toulouse, France; \\ desouto-barreto.p@chu-toulouse.fr (P.D.S.B.); rolland.y@chu-toulouse.fr (Y.R.); vellas.b@chu-toulouse.fr (B.V.) \\ 3 Center for Epidemiology and Research in POPulation Health (CERPOP), UMR 1295, Inserm, \\ UPS Toulouse III University, 31000 Toulouse, France; costa.n@chu-toulouse.fr (N.C.); \\ molinier.1@chu-toulouse.fr (L.M.) \\ 4 Economic Evaluation Unit, Medical Information Department, Toulouse University Hospital, \\ 31000 Toulouse, France \\ * Correspondence: pages.ar@chu-toulouse.fr; Tel.: +33-567-776-418 \\ + Members of MAPT/DSA Group are listed at the end of the manuscript.
}

Citation: Pagès, A.; Rouch, L.; Costa, N.; Cestac, P.; De Souto Barreto, P.; Rolland, Y.; Vellas, B.; Molinier, L.; Juillard-Condat, B.; MAPT /DSA Group. Potentially Inappropriate Medication Prescribing Detected by Computer Algorithm among Older Patients: Results from the MAPT Study. Pharmacy 2021, 9, 189. https://doi.org/10.3390/pharmacy 9040189

Academic Editor: David Wright

Received: 13 August 2021

Accepted: 22 November 2021

Published: 24 November 2021

Publisher's Note: MDPI stays neutral with regard to jurisdictional claims in published maps and institutional affiliations.

Copyright: (C) 2021 by the authors. Licensee MDPI, Basel, Switzerland. This article is an open access article distributed under the terms and conditions of the Creative Commons Attribution (CC BY) license (https:/ / creativecommons.org/licenses/by/ $4.0 /)$.
Abstract: (1) Background: Some medications may be dangerous for older patients. Potentially inappropriate medication prescribing (PIP) among older patients represents a significant cause of morbidity. The aim of this study was to create an algorithm to detect PIP in a geriatric database (Multidomain Alzheimer Preventive Trial (MAPT) study), and then to assess the algorithm construct validity by comparing the prevalence of PIP and associated factors with literature data. (2) Methods: An algorithm was constructed to detect PIP and was based on different explicit criteria among which the European list of potentially inappropriate medications (EU(7)-PIM), the STOPP and START version 2 tools. For construct validity assessment, logistic mixed-effects model repeated measures analyses were used to identify factors associated with PIP. (3) Results: Prevalence of PIP was 59.0\% with the EU(7)-PIM list criteria, 43.2\% with the STOPP criteria and 51.3\% with the START criteria. Age, polypharmacy, and higher Charlson comorbidity index were associated with PIP. (4) Conclusions: Prevalence of PIP and associated factors are consistent with literature data, supporting the construct validity of our algorithm. This algorithm opens up interesting perspectives both in terms of analysis of very large databases and integration into e-prescribing or pharmaceutical validation software.

Keywords: potentially inappropriate medication prescribing; medication; elderly; algorithm; database

\section{Introduction}

Older patients, who often suffer from multiple comorbidities and take multiple medications, are particularly at risk for potentially inappropriate use of medications, including overuse, underuse, and misuse. A recent meta-analysis showed an association between potentially inappropriate medication prescriptions (PIPs) and the risk of adverse effects and hospitalizations in older subjects [1].

Several tools have been developed to make PIPs identification easier, based on explicit or implicit approaches, or a combination of both. The implicit approach is based on clinical judgment: the risk/benefit ratio of each medication is analyzed with regard to medical history, comorbidities, laboratory tests, and co-prescribed medications. The Medication Appropriateness Index (MAI) developed by Hanlon et al. is based on this approach, which is characterized by significant inter-observer variability [2]. The explicit approach is based on criteria that are derived from expert consensus. These criteria are simple to use and 
can be applied in the same way in all patients, regardless of individual characteristics. It involves standardized lists of medications to be avoided in older patients [3,4]. A literature review identified 36 validated explicit criteria-based tools for identifying PIPs in older people [5]. Initially, these were simple lists of potentially inappropriate medications (Beers Criteria, and the European List of Potentially Inappropriate Medications for Older People (EU(7)-PIM)) [3,6]. These tools gradually became more complex, in the form of multiplecriteria rules that incorporated clinical and laboratory data [4]. This made them more sensitive but less practical to use [4].

PIP identification tools are used both in routine practice to improve individual patient safety and in research to measure PIPs frequency and give insight into the risk factors associated with PIPs. In this second case, PIPs are detected in large databases, using either lists of potentially inappropriate medications [7] or algorithms that translate multiple criteria rules [8]. The algorithms integrating the clinical, biological and prescription data were first designed to detect potentially inappropriate medications $[9,10]$ and then permitted to detect both prescriptions omissions and potentially inappropriate medications, based on STOPP/START v1 criteria [11]. An algorithm based on several rules (START and STOPP v2 criteria and the Beers Criteria) is announced in the COME-ON study protocol (Collaborative approach to Optimize MEdication use for Older people in Nursing homes) $[8,12]$.

In this context, the first objective of this study was to develop an algorithm to detect both inappropriate medications, major drugs interactions and prescriptions omissions, based on four explicit criteria-based tools (including the EU(7)-PIM list and START and STOPP v2 criteria). The secondary objective was to test the applicability of the algorithm on a large geriatric database and to assess its construct validity by identifying factors that have previously shown a relationship with PIP.

\section{Materials and Methods}

\subsection{Database}

We used the data from the Multidomain Alzheimer Preventive Trial (MAPT) to conduct a longitudinal secondary analysis. The Multidomain Alzheimer Preventive Trial (MAPT) was a 3-year, multicenter (13 memory centers in France and Monaco), randomized trial aimed to test the preventive effect of omega-3 supplementation or multidomain intervention (nutritional and exercise counseling and cognitive training) or both on dementia and follow-up data every 6 months. Participants were aged 70 years or older, and community-dwelling without dementia or any difficulty in basic activities of daily living (ADL) [13] at baseline. The multidomain intervention was not focused on medication review [14]. The trial protocol was approved by the French Ethical Committee located in Toulouse (CPP SOOM II). This specific secondary analysis was approved for ethics and feasibility by the Multidomain Alzheimer Preventive Trial/Data Sharing Alzheimer (MAPT/DSA) Group (Appendix A).

The database included prescription and over-the-counter (OTC) medications, with the medication name, International Non-proprietary Name, Anatomical Therapeutic Chemical (ATC) fifth level class (classification system of active substances according to their target organs and their chemical, pharmacological or therapeutic properties, 5th level is the chemical substance), dosage, and start and end dates. Comorbidities (free text coded) and their date of onset were available in the database. We calculated the Charlson comorbidity index for each patient at baseline [15]. The database also contained other clinical parameters (Fried frailty phenotype [16], systolic and diastolic blood pressure in supine and standing positions, heart rate, geriatric depression scale (GDS) [17], etc.). 


\subsection{Algorithm}

We developed our own computerized PIP detection algorithm from various explicit criteria-based tools:

- The European List of Potentially Inappropriate Medications in Older People (EU(7)PIM list) [3].

- The STOPP and START version 2 criteria (Screening Tool of Older People's Prescriptions and Screening Tool to Alert to Right Treatment) [4].

- Clinical practice indicators of Alert and Mastering of medication Iatrogenicity (AMI) proposed by the French National Authority for Health (HAS) related to medication prescriptions in older patients [18].

- Market withdrawals by the French National Agency for Medicines and Health Products Safety (ANSM) or the European Medicines Agency (EMA) for safety reasons.

- Contraindications listed in the medications' Summary of Product Characteristics (SmPC).

As there are many explicit criteria tools available, we chose EU(7)-PIM list, the STOPP and START version 2 criteria because they were the most recent tools in Europe. In addition, they were validated for both inpatients and outpatients and the combination of the two allowed us to detect situations of overuse, misuse and underuse [5]. We added three other tools to comply with the recommendations of French and European health agencies related to medication prescription. We identified market withdrawals manually from the websites of the agencies concerned and identified contraindications by querying a medication database approved by the French National Authority for Health. During this development, we identified contradictions or redundancies between the various explicit criteria-based tools. The choice of the combination of several criteria was guided by the objective of relating as much as possible to the pharmaceutical analysis carried out by a clinical pharmacist who uses all available sources.

A clinical pharmacist with expertise in geriatrics coded explicit criteria. Another pharmacist then checked the entire coding. In case of disagreement on a part of the code, a conciliation was performed and a decision was made by consensus between the two pharmacists. The programming of the computer algorithm was performed with SAS@ 9.3 software (SAS Institute Inc., Cary, NC, USA).

Some explicit criteria required methodological choices for coding. For the STOPP A1 criterion "Any medication prescribed without an evidence-based clinical indication", we only coded two sub-criteria proposed by a panel of Belgian, Canadian, French and Swiss experts (1: aspirin and statin in primary cardiovascular prevention, 2: proton pump inhibitor without recent oesogastric damage) [19]. For the STOPP B6 criterion "Loop diuretic as first-line treatment for hypertension", we considered hypertensive patients with a loop diuretic, without heart failure, liver failure, nephrotic or renal syndrome and without any other concomitant antihypertensive medication. For the START G1 and G2 criteria related respectively to alpha-1 receptor blocker and alpha reductase inhibitor with symptomatic prostatism, we could not consider "where prostatectomy is not necessary", we only considered whether prostatectomy had been performed. In addition, dosage information was used to distinguish medicines indications (e.g., antiplatelet agents vs. non-steroidal anti-inflammatory medications) or to clarify the coding of certain criteria.

Some criteria were not considered relevant for coding. The STOPP K1 (benzodiazepines), K2 (neuroleptic drugs), and K4 (hypnotic Z-drugs) criteria were considered too broad to be clinically relevant to assessors, and appeared to be partially redundant with other more specific criteria (e.g., STOPP D3, D5, or G4 criteria). The START C3 criterion "acetylcholinesterase inhibitor for mild/moderate Alzheimer's dementia or Lewy Body dementia" was not taken into account since these medications are no longer recommended in France. Six clinical practice indicators AMI were considered to be prescription monitoring criteria more than PIP detection criteria, and therefore, were not coded. The other uncoded criteria were related to the unavailability of certain variables in the database.

Then, the computer algorithm was used on the database combining the different datasets (medication prescription, comorbidities, clinical data (e.g., blood pressure, as- 
sessment of frailty)) of the MAPT study. The computer algorithm generated a number of medication-related potential noncompliances (MRNC) by prescription at each follow-up time. We took into account strict duplicates between tools when counting the number of MRNC. A medication prescription was considered potentially inappropriate (PIP) if it included at least one MRNC. The PIP variable was thus coded in a binary manner for each patient and each follow-up time.

\subsection{Statistical Analysis}

As we made the hypothesis that data were missing at random (MAR), the missing data were imputed by Multiple Imputation by Chained Equations (MICE) [20] if it exceeded 1\%. The baseline numbers and percentages for the categorical variables were presented; comparisons were made using the $\chi^{2}$ test (or Fisher's exact test (for expected values $<5$ )). To verify the construct validity of the computer algorithm, we performed a multivariate analysis to assess the association between patient characteristics (age, gender, number of medications prescribed, Charlson comorbidity index, education level, frailty) and PIP. These patient characteristics were chosen because they were frequently associated with PIP in other studies [21,22]. We also introduced MAPT intervention groups and follow-up time (categorical variable) in the model. The age groups were defined according to two thresholds: 75 years and 80 years [18]. We categorized the number of medications prescribed into three categories: non-polypharmacy ( $0-4$ medications), polypharmacy (5-9 medications), and hyperpolypharmacy (10 or more medications) [23]. Polypharmacy, frailty and PIP were considered as time-varying variables. We conducted a multivariate analysis using a mixed logistic regression model with a random effect at the level of patients to consider the correlation of observations for a single individual (repeated measures) and fixed effects for other variables [24]. The results were presented as an odds ratio for each variable included in the analysis. All hypothesis testing was performed using a 5\% significance level ( $p$ values and corresponding $95 \%$ confidence intervals for each odds ratio). The model programming and statistical analyses were done using the software SASC 9.3 (SAS Institute Inc., Cary, NC, USA).

\section{Results}

The solution procedure flow chart of the computerized PIP detection algorithm is presented in Figure 1. The coded criteria and information used, and the strict redundancies, are explained in Table S1 in the Supplementary Material. We were able to code 47 of 80 STOPP criteria, 24 of 34 START criteria, five of 11 AMI criteria, and the entire European list EU(7)-PIM (282 medications or medication classes), 21 marketing authorization (MA) withdrawals and 7457 contraindications. Overall, the algorithm analyzed 9643 medication prescriptions from 1525 patients.

Baseline characteristics are shown in Table 1, and the percentage of patients according to the number of MRNCs is presented in Figure 2. At baseline, frailty assessment and education level were missing in $5 \%$ and $2 \%$ of cases respectively.

At baseline, before accounting for duplicates between the tools, out of 1525 patients, we found at least one PIP in 900 patients (59.0\%) with the EU(7)-PIM list criteria, 659 patients $(43.2 \%)$ with the STOPP criteria, 783 patients (51.3\%) with the START criteria, 212 patients (13.9\%) with the French AMI criteria; for 13 patients (0.9\%) a contraindication due to possible drug interaction was detected in the prescription (Table 2).

Regarding the construct validity assessment of the computer algorithm, we found that age, polypharmacy, and higher Charlson comorbidity index were associated with PIP in the multivariate analysis (Table 3). 


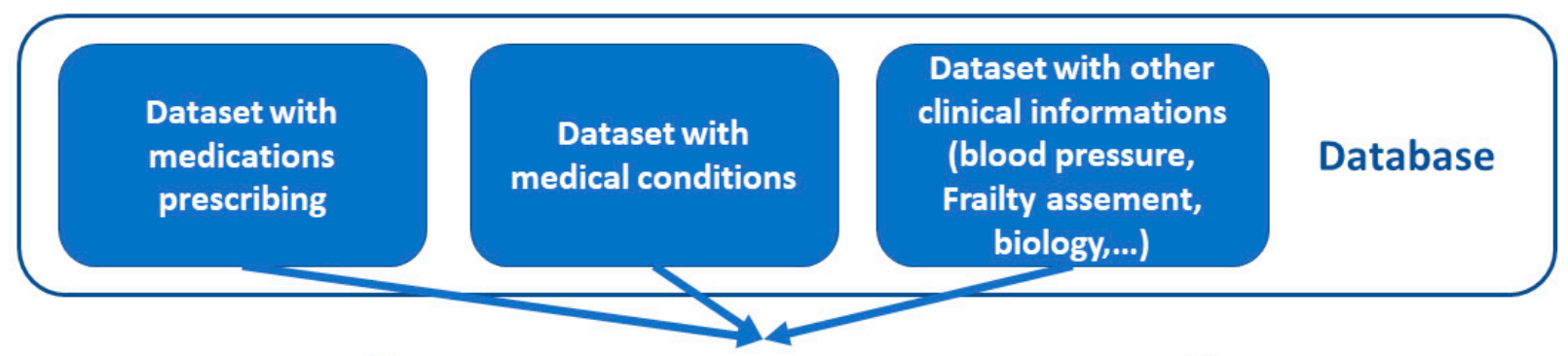

Creation of several databases associating datasets according to different combination modalities

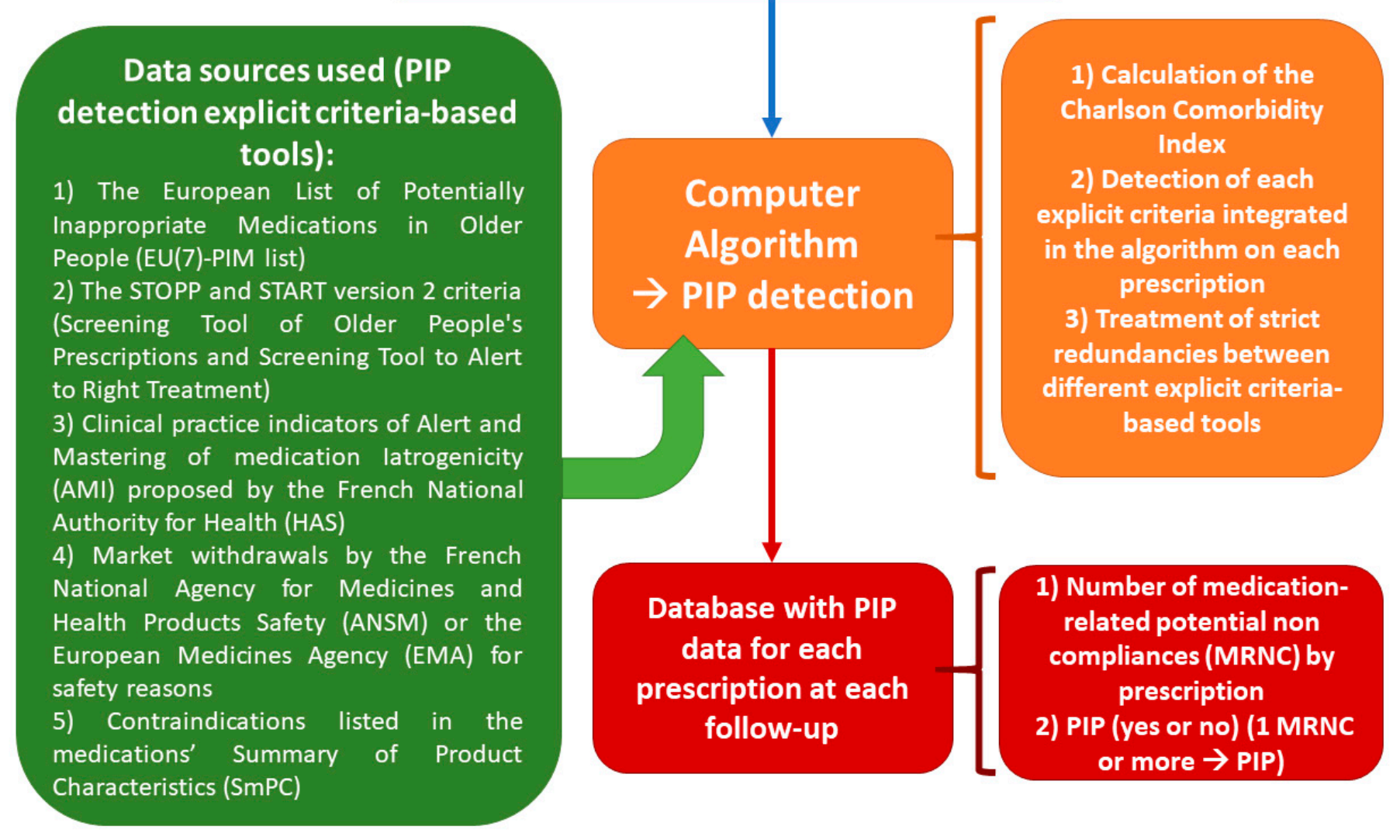

Legend: PIP, potentially inappropriate medication prescribing.

Figure 1. Solution procedure flow chart of the Computer Algorithm.

Table 1. Baseline characteristics of patients with and without a potentially inappropriate medication prescribing (PIP).

\begin{tabular}{|c|c|c|c|c|}
\hline \multirow[b]{2}{*}{ Baseline Characteristics } & \multicolumn{2}{|c|}{ Appropriateness Medication Prescribing } & \multirow[b]{2}{*}{ Total $(n=1525)$} & \multirow[b]{2}{*}{$p$-Value } \\
\hline & $\begin{array}{l}\text { without PIP } \\
\quad(\mathrm{n}=287)\end{array}$ & $\begin{array}{l}\text { with PIP } \\
(\mathrm{n}=1238)\end{array}$ & & \\
\hline \multicolumn{5}{|l|}{ Gender, n (\%) } \\
\hline Female & $187(65 \%)$ & $791(64 \%)$ & $978(64 \%)$ & \multirow{2}{*}{0.688} \\
\hline Male & $100(35 \%)$ & $447(36 \%)$ & $547(36 \%)$ & \\
\hline \multicolumn{5}{|l|}{ Age (Years), n (\%) } \\
\hline Age $\leq 74$ years & $182(63 \%)$ & $581(47 \%)$ & $763(50 \%)$ & \multirow{3}{*}{$<0.001$} \\
\hline 75 years $\leq$ Age $\leq 79$ years & $74(26 \%)$ & $415(33 \%)$ & $489(32 \%)$ & \\
\hline Age $\geq 80$ years & $31(11 \%)$ & $242(20 \%)$ & $273(18 \%)$ & \\
\hline
\end{tabular}


Table 1. Cont.

\begin{tabular}{|c|c|c|c|c|}
\hline \multirow[b]{2}{*}{ Baseline Characteristics } & \multicolumn{2}{|c|}{ Appropriateness Medication Prescribing } & \multirow[b]{2}{*}{ Total $(n=1525)$} & \multirow[b]{2}{*}{$p$-Value } \\
\hline & $\begin{array}{l}\text { without PIP } \\
\quad(n=287)\end{array}$ & $\begin{array}{c}\text { with PIP } \\
(n=1238)\end{array}$ & & \\
\hline \multicolumn{5}{|l|}{ Education, $\mathrm{n}(\%) *$} \\
\hline $\begin{array}{l}\text { No diploma or primary school } \\
\text { certificate }\end{array}$ & $59(21 \%)$ & $275(23 \%)$ & $334(22 \%)$ & \multirow{4}{*}{0.291} \\
\hline Secondary education & $95(34 \%)$ & $416(34 \%)$ & $511(34 \%)$ & \\
\hline High school diploma & $51(18 \%)$ & $167(14 \%)$ & $218(15 \%)$ & \\
\hline University level & $77(27 \%)$ & $361(29 \%)$ & $438(29 \%)$ & \\
\hline \multicolumn{5}{|l|}{ Intervention Group, $\mathrm{n}(\%)$} \\
\hline $\begin{array}{l}\text { Multidomain plus } \\
\text { polyunsaturated fatty acids }\end{array}$ & $68(24 \%)$ & $306(25 \%)$ & $374(24 \%)$ & \multirow{4}{*}{0.226} \\
\hline Polyunsaturated fatty acids & $60(21 \%)$ & $321(26 \%)$ & $381(25 \%)$ & \\
\hline Multidomain plus placebo & $83(29 \%)$ & $307(25 \%)$ & $390(26 \%)$ & \\
\hline Placebo & $76(26 \%)$ & $304(24 \%)$ & $380(25 \%)$ & \\
\hline \multirow{2}{*}{\multicolumn{5}{|c|}{$\begin{array}{c}\text { Number of Medications } \\
\text { Prescribed }\end{array}$}} \\
\hline & & & & \multirow{4}{*}{$<0.001$} \\
\hline $\begin{array}{c}\text { Number of medications } \\
\text { prescribed } \leq 4\end{array}$ & $255(89 \%)$ & $557(45 \%)$ & $812(53 \%)$ & \\
\hline $\begin{array}{c}5 \leq \text { Number of medications } \\
\text { prescribed } \leq 9 \text { (polypharmacy) }\end{array}$ & $32(11 \%)$ & $557(45 \%)$ & $589(39 \%)$ & \\
\hline $\begin{array}{c}\text { Number of medications } \\
\text { prescribed } \geq 10 \\
\text { (hyperpolypharmacy) }\end{array}$ & $0(0 \%)$ & $124(10 \%)$ & $124(8 \%)$ & \\
\hline \multicolumn{5}{|l|}{$\begin{array}{c}\text { Charlson Comorbidity Index, } \mathrm{n} \\
(\%)\end{array}$} \\
\hline 0 point & $269(94 \%)$ & $915(74 \%)$ & $1184(78 \%)$ & \multirow{3}{*}{$<0.001$} \\
\hline 1 point & $16(5 \%)$ & $232(19 \%)$ & $248(16 \%)$ & \\
\hline$\geq 2$ points & $2(1 \%)$ & $91(7 \%)$ & $93(6 \%)$ & \\
\hline \multicolumn{5}{|l|}{ Frailty, n (\%) ** } \\
\hline Robust patients & $187(69 \%)$ & $612(52 \%)$ & $799(55 \%)$ & \multirow{3}{*}{$<0.001$} \\
\hline Prefrail patients & $79(29 \%)$ & $524(45 \%)$ & $603(42 \%)$ & \\
\hline Frail patients & $5(2 \%)$ & $38(3 \%)$ & $43(3 \%)$ & \\
\hline \multicolumn{5}{|l|}{$\begin{array}{l}\text { Instrumental Activities of } \\
\text { Daily Living, n (\%) }\end{array}$} \\
\hline $\begin{array}{l}\text { IADL }=8 \text { (no deficit on } \\
\text { instrumental activities) }\end{array}$ & $277(97 \%)$ & $1181(95 \%)$ & $1458(96 \%)$ & \multirow[t]{2}{*}{0.192} \\
\hline $\begin{array}{c}\text { IADL > } 8 \text { (deficit on } \\
\text { instrumental activities) }\end{array}$ & $8(3 \%)$ & $56(5 \%)$ & $64(4 \%)$ & \\
\hline \multicolumn{5}{|l|}{ Medical Conditions, n (\%) } \\
\hline Hypertension & $157(55 \%)$ & $857(69 \%)$ & $1014(66 \%)$ & $<0.001$ \\
\hline Myocardial infarction & $0(0 \%)$ & $88(7 \%)$ & $88(6 \%)$ & $<0.001$ \\
\hline Heart failure & $2(1 \%)$ & $65(5 \%)$ & $67(4 \%)$ & $<0.001$ \\
\hline Peripheral vascular disease & $3(1 \%)$ & $43(3 \%)$ & $46(3 \%)$ & 0.030 \\
\hline $\begin{array}{l}\text { Cerebrovascular accident or } \\
\text { transient ischemic attack }\end{array}$ & $1(0 \%)$ & $41(3 \%)$ & $42(3 \%)$ & 0.006 \\
\hline $\begin{array}{l}\text { Chronic obstructive pulmonary } \\
\text { disease }\end{array}$ & $1(0 \%)$ & $41(3 \%)$ & $42(3 \%)$ & 0.006 \\
\hline Peptic ulcer disease & $7(2 \%)$ & $58(5 \%)$ & $65(4 \%)$ & 0.090 \\
\hline Diabetes mellitus \# & $0(0 \%)$ & $13(1 \%)$ & $13(1 \%)$ & 0.145 \\
\hline Severe chronic kidney disease \# & $1(0 \%)$ & $7(1 \%)$ & $8(1 \%)$ & 0.999 \\
\hline Cancer \# & $0(0 \%)$ & $9(1 \%)$ & $9(1 \%)$ & 0.223 \\
\hline
\end{tabular}




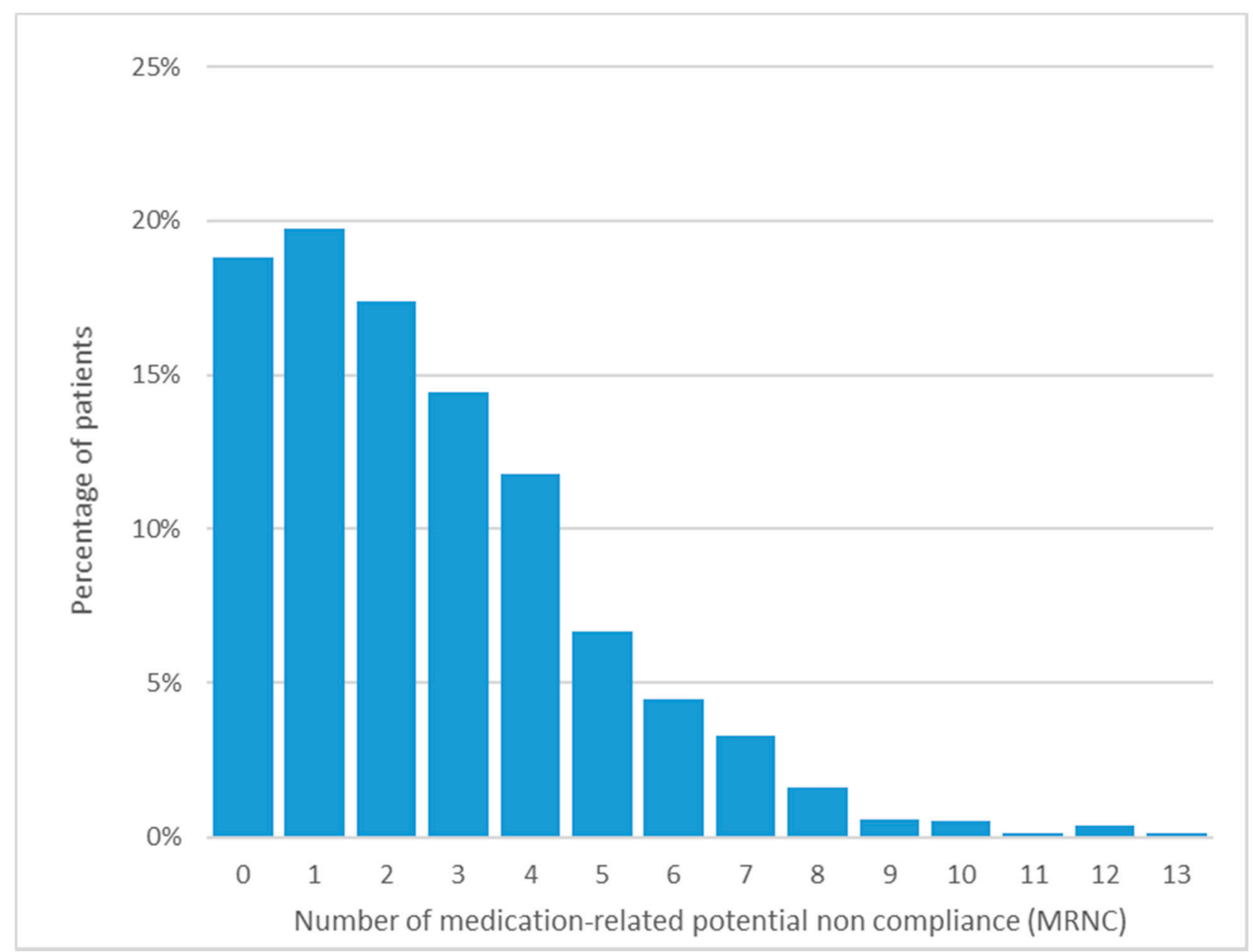

Figure 2. Percentage of medication-related potential noncompliance occurrences at baseline.

Table 2. Percentage of potentially inappropriate medication prescribing (PIP) criteria occurrence at baseline.

- European List of Potentially Inappropriate Medications in Older People (EU(7)-PIM list)

- Screening Tool to Alert to Right Treatment (START) version 2

- Screening Tool of Older Persons' Prescriptions (STOPP) version 2

- Clinical practice indicators of Alert and Mastering of medication Iatrogenicity (AMI)

proposed by the French National Authority for Health (HAS) related to medication prescriptions in older subjects

- Market withdrawals by the French National Agency for Medicines and Health Products

Safety (ANSM) or the European Medicines Agency (EMA) for safety reasons

- Contraindications listed in the medications' Summary of Product Characteristics (SmPC)
$900(59 \%)$

$783(51 \%)$

$659(43 \%)$

$212(14 \%)$

$13(1 \%)$

Legend: PIP = potentially inappropriate medication prescribing.

Table 3. Factors associated with variation over time of potentially inappropriate medication prescribing (PIP).

\begin{tabular}{ccc}
\hline Parameters & Adjusted * Odds Ratio [95CI] & $p$-Value \\
Gender & \\
Female & Ref. \\
Male & $0.82[0.38 ; 1.74]$ & 0.601 \\
Age (Years) & & \\
Age $\leq 74$ years & Ref. \\
75 years $\leq$ Age $\leq 79$ years & $2.75[1.24 ; 6.09]$ \\
Age $\geq 80$ years & $5.36[1.86 ; 15.44]$ & 0.003 \\
\hline
\end{tabular}


Table 3. Cont.

\begin{tabular}{|c|c|c|}
\hline Parameters & Adjusted * Odds Ratio [95CI] & $p$-Value \\
\hline $\begin{array}{c}\text { Education } \\
\text { No diploma or primary school certificate } \\
\text { Secondary education } \\
\text { High school diploma } \\
\text { University level }\end{array}$ & $\begin{array}{c}\text { Ref. } \\
1.45[0.61 ; 3.47] \\
0.87[0.30 ; 2.51] \\
1.57[0.64 ; 3.86]\end{array}$ & 0.590 \\
\hline $\begin{array}{c}\text { Intervention Group } \\
\text { Placebo } \\
\text { Multidomain plus polyunsaturated fatty acids } \\
\text { Polyunsaturated fatty acids } \\
\text { Multidomain plus placebo }\end{array}$ & $\begin{array}{c}\text { Ref. } \\
1.25[0.47 ; 3.34] \\
2.48[0.92 ; 6.66] \\
1.20[0.46 ; 3.12]\end{array}$ & 0.308 \\
\hline $\begin{array}{c}\text { Number of Drugs Prescribed } \\
\text { Number of drugs prescribed } \leq 4 \\
5 \leq \text { Number of drugs prescribed } \leq 9 \\
\text { (polypharmacy) } \\
\text { Number of drugs prescribed } \geq 10 \\
\text { (hyperpolypharmacy) }\end{array}$ & $\begin{array}{c}\text { Ref. } \\
26.64[12.29 ; 57.73] \\
662.16[76.85 ; 5705.28]\end{array}$ & $<0.001$ \\
\hline $\begin{array}{c}\text { Charlson Comorbidity Index (Baseline) } \\
0 \text { point } \\
1 \text { point } \\
\geq 2 \text { points }\end{array}$ & $\begin{array}{c}\text { Ref. } \\
10.89[3.17 ; 37.35] \\
21.93[1.48 ; 324.44]\end{array}$ & $<0.001$ \\
\hline $\begin{array}{l}\text { Frailty } \\
\text { Robust patients } \\
\text { Prefrail patients } \\
\text { Frail patients }\end{array}$ & $\begin{array}{c}\text { Ref. } \\
1.33[0.96 ; 1.84] \\
1.95[0.69 ; 5.52]\end{array}$ & 0.151 \\
\hline
\end{tabular}

Legend: PIP = potentially inappropriate medication prescribing; $95 \mathrm{CI}=95 \%$ confidence interval, ${ }^{*}$ also adjusted on follow-up time (categorical variable: each 6-month follow-up visit).

\section{Discussion and Conclusions}

We incorporated in the computer algorithm the entire EU(7)-PIM list, 59\% (47/80) of STOPP criteria and 70\% (24/34) of START criteria. Prevalence of PIP was 59.0\% with EU(7)-PIM list criteria, $43.2 \%$ with STOPP criteria and 51.3\% with START criteria. In the multivariate analysis, we found older age, polypharmacy, and a high comorbidity index to be associated factors with PIPs. Conversely, neither the intervention group of the MAPT study nor the level of education was associated with PIPs.

It should be emphasized that PIP detection tools were first designed for use by clinicians, who have complete clinical data as well as the patient's care history. Coding of these tools within algorithms, followed by application of algorithms to research databases, both lead to several limits.

Firstly, the main encoding difficulties arise from the fact that some criteria are not precisely defined and leave a margin of interpretation; others need clarification to avoid false positives [8]. Secondly, PIP detection on large research databases may be limited by the unavailability of clinical or biological data. In fact, $85 \%$ of the STOPP criteria and $97 \%$ of the START criteria require other information in addition to medication prescription data (laboratory and clinical parameters, or medication histories) [8]. In our study, the combination of our coding and data available in the database allowed us to take into account $59 \%$ of STOPP criteria and $70 \%$ of START criteria, which is literature data: respectively $40 \%$ and $59 \%$ of STOPP and START v1 criteria were applied on a database of 3454 Irish adults aged $\geq 65$ years [25]; Nauta et al. were able to apply $63 \%$ of the STOPP v1 criteria and $69 \%$ of the START v1 criteria on a Dutch primary care database, including 1187 patients aged $\geq 65$ years [11]. Regarding validation of computer algorithms applied to research databases, Nauta et al. stress that there is no gold standard for evaluating the appropriateness of a prescription, and choose to estimate the validity of how its algorithm is built by comparing the characteristics of the PIPs detected with those found in published 
studies [11]. Two characteristics can be compared: prevalence of PIP, and factors associated with PIP.

First, it must be emphasized that PIP prevalence assessed on a large database using algorithms should not be considered as a reliable indicator of the clinical relevance of prescriptions: in our study, potential inappropriateness is considered as a dichotomized variable, and results are only intended to validate the construction of the algorithm. The comparability of the PIP prevalence results is mostly limited by criteria actually coded during detection by computer algorithm, and less importantly by differences in patients' characteristics (outpatients or inpatients, age), and the PIP detection methods used (implicit and/or explicit approach) [21]. In our study on 1525 outpatients over age 70, the prevalence of patients whose prescription contains at least one STOPP alert is $43.2 \%$ ( 47 criteria evaluated), one START alert 51.3\% (24 criteria evaluated), one EU(7)-PIM list alert $59.0 \%$, respectively.

A study performed on 38,229 outpatients over age 65, with START and STOPP v2 criteria (45 STOPP criteria evaluated) showed that the prevalence of PIP was $45.3 \%$ in 2012 and $51.0 \%$ in 2015 [26]. One other study estimated that-out of 503 outpatients- $56 \%$ had a PIP according to STOPP v2 criteria (46/80 coded criteria) and $67 \%$ PPO according to START v2 criteria (13/34 coded criteria) [27]. The higher prevalence relative to our study can be explained by an older population ( $>80$ years). Regarding PIP detection based on the EU(7)-PIM list, one Lithuanian retrospective, population-based study $(n=431,625)$ of patients over age 65 , estimated a prevalence of $57.2 \%$, close to that found in our study (59.0\%) [7].

Regarding factors associated with PIP, we found in the multivariate analysis that age, polypharmacy, and higher Charlson comorbidity index are associated with PIP. The finding of the association between PIP and age, polypharmacy, and morbidity established in multivariate analyses is widely consistent with other published studies, that enforce the construct validity of the computer algorithm. According to the review by Tommelein et al., all of the publications analyzed (27/27) show an association between PIP and polypharmacy, more than half $(6 / 10)$ between PIP and comorbidities, and nearly half $(12 / 25)$ between PIP and advanced age [21]. This is linked to the fact that age and comorbidity score increase polypharmacy, and therefore, the likelihood of having an inappropriate medication. Likewise, the number of comorbidities also increases with age. Regarding other factors identified in our study, Gallagher et al., also show a correlation between potential prescribing omissions and the Charlson comorbidity index [28]. Muhlack et al. show an association between PIPs and frailty, but only for Beers Criteria in patients with dementia [22].

Our study has strengths. First, we designed a computer algorithm to detect PIPs, based on four explicit criteria-based tools and also major drugs interactions, whereas previous studies only integrated one or two explicit criteria-based tools. As the database included over-the-counter (OTC) medications, we can evaluated the appropriateness of using OTC because the EU(7)-PIM list contains OTC medications. Clinical and biological data available in our database allowed us to encode the majority of START and STOPP v2 criteria. Then, we tested the applicability of this computer algorithm on a large longitudinal geriatric database. Several factors support the construct validity of our algorithm. First, the coding of criteria was defined by consensus between pharmacists and double-checked. Then, we found that factors associated with PIPs in our study were consistent with literature data. The main limitation of this study is that the PIP detection computer algorithm was not validated by comparison with human pharmaceutical analysis. Yet such a manual screening of the prescriptions raises two difficulties: firstly, it should only be based on the explicit criteria selected in the study, and secondly, it may concern only a sample of the 9643 prescriptions database.

Future research may also compare PIP detection using an algorithm, with PIP detection based on explicit and implicit approaches conducted by professionals. This comparison would provide information on the performance of the algorithm, and it would help identify the respective contributions of algorithms and humans in analyzing medication prescrip- 
tions in older subjects. This information would also allow us to improve the algorithm's computer code to make it better reflect clinical practice.

The explicit criteria-based tools used to develop the computer algorithm were adapted for all elderly people. However, our population was not representative of the entire elderly population since the MAPT study included only community-dwelling patients aged 70 years or older, without dementia or any difficulty in basic activities of daily living (ADL) at baseline, and particularly well educated [14]. It could also be interesting to apply our computer algorithm on databases of dependent or dementia patients in nursing homes.

This computerized PIP detection algorithm was created from several data sources. It opens up some interesting perspectives, both in terms of analyzing very large databases and for its integration into e-prescription or pharmaceutical validation software.

Supplementary Materials: The following are available online at https:/ / www.mdpi.com/article/ 10.3390/pharmacy9040189/s1, Table S1: Details about the potentially inappropriate medication prescribing detection algorithm

Author Contributions: Conceptualization, A.P., L.R., N.C., P.C., P.D.S.B., Y.R., B.V., L.M., B.J.-C. and MAPT/DSA Group; data collecting, A.P., N.C. and L.M.; methodology, N.C., L.R., P.C., P.D.S.B., Y.R., B.V. and L.M.; software, A.P. and B.J.-C.; data analysis, A.P. and B.J.-C.; investigation, N.C., L.R., P.C., P.D.S.B., Y.R., B.V. and L.M.; data interpretation, A.P., L.R., N.C., P.C., P.D.S.B., Y.R., B.V., L.M., B.J.-C. and MAPT/DSA Group; writing—original draft preparation, A.P., L.R. and B.J.-C.; writing—review and editing, A.P., L.R. and B.J.-C. All authors have read and agreed to the published version of the manuscript.

Funding: The MAPT study was supported by grants from the Gérontopôle of Toulouse, the French Ministry of Health (PHRC 2008, 2009), Pierre Fabre Research Institute (manufacturer of the omega-3 supplement), ExonHit Therapeutics SA, and Avid Radiopharmaceuticals Inc. The promotion of the MAPT study was supported by the University Hospital Center of Toulouse. The data sharing activity was supported by the Association Monegasque pour la Recherche sur la maladie d'Alzheimer (AMPA) and the UMR 1295 Unit INSERM-University of Toulouse III.

Institutional Review Board Statement: The trial protocol was approved by the French Ethical Committee for the Protection of Persons (CPP SOOM II) and was authorized by the French National Agency for Medicines and Health Products Safety. The trial was registered in ClinicalTrials.gov, accessed on 13 August 2021, (NCT00672685). This specific secondary analysis was approved for ethics and feasibility by the Multidomain Alzheimer Preventive Trial/Data Sharing Alzheimer (MAPT/DSA) Group.

Informed Consent Statement: All participants were recruited by the investigators, who verified inclusion and exclusion criteria and obtained written informed consent.

Data Availability Statement: The MAPT data are available upon request, following validation of a research proposal, from Multidomain Alzheimer Preventive Trial/Data Sharing Alzheimer (MAPT/DSA) Group (nicola.coley@inserm.fr or guyonnet.s@chu-toulouse.fr).

Acknowledgments: This study was conducted as part of the Inspire Program, a research platform supported by grants from the Occitanie/Pyrénées-Méditerranée Region (Reference number: 1901175) and the European Regional Development Fund (ERDF) (Project number: MP0022856).

Conflicts of Interest: The authors declare that they have no conflict of interest.

\section{Appendix A. MAPT/DSA Group}

Appendix A.1. MAPT Study Group

Principal investigator: Bruno Vellas (Toulouse); Coordinator: Sophie Guyonnet; Project leader: Isabelle Carrié; $C R A$ : Lauréane Brigitte; Investigators: Catherine Faisant, Françoise Lala, Julien Delrieu, Hélène Villars; Psychologists: Emeline Combrouze, Carole Badufle, Audrey Zueras; Methodology, statistical analysis and data management: Sandrine Andrieu, Christelle Cantet, Christophe Morin; Multidomain group: Gabor Abellan Van Kan, Charlotte Dupuy, Yves Rolland (physical and nutritional components), Céline Caillaud, Pierre-Jean Ousset (cognitive component), Françoise Lala (preventive consultation). The cognitive com- 
ponent was designed in collaboration with Sherry Willis from the University of Seattle and Sylvie Belleville, Brigitte Gilbert and Francine Fontaine from the University of Montreal.

Co-Investigators in associated centers: Jean-François Dartigues, Isabelle Marcet, Fleur Delva, Alexandra Foubert, Sandrine Cerda (Bordeaux); Marie-Noëlle-Cuffi, Corinne Costes (Castres); Olivier Rouaud, Patrick Manckoundia, Valérie Quipourt, Sophie Marilier, Evelyne Franon (Dijon); Lawrence Bories, Marie-Laure Pader, Marie-France Basset, Bruno Lapoujade, Valérie Faure, Michael Li Yung Tong, Christine Malick-Loiseau, Evelyne Cazaban-Campistron (Foix); Françoise Desclaux, Colette Blatge (Lavaur); Thierry Dantoine, Cécile Laubarie-Mouret, Isabelle Saulnier, Jean-Pierre Clément, Marie-Agnès Picat, Laurence Bernard-Bourzeix, Stéphanie Willebois, Iléana Désormais, Noëlle Cardinaud (Limoges); Marc Bonnefoy, Pierre Livet, Pascale Rebaudet, Claire Gédéon, Catherine Burdet, Flavien Terracol (Lyon), Alain Pesce, Stéphanie Roth, Sylvie Chaillou, Sandrine Louchart (Monaco); Kristel Sudres, Nicolas Lebrun, Nadège Barro-Belaygues (Montauban); Jacques Touchon, Karim Bennys, Audrey Gabelle, Aurélia Romano, Lynda Touati, Cécilia Marelli, Cécile Pays (Montpellier); Philippe Robert, Franck Le Duff, Claire Gervais, Sébastien Gonfrier (Nice); Yannick Gasnier and Serge Bordes, Danièle Begorre, Christian Carpuat, Khaled Khales, Jean-François Lefebvre, Samira Misbah El Idrissi, Pierre Skolil, Jean-Pierre Salles (Tarbes).

MRI group: Carole Dufouil (Bordeaux), Stéphane Lehéricy, Marie Chupin, JeanFrançois Mangin, Ali Bouhayia (Paris); Michèle Allard (Bordeaux); Frédéric Ricolfi (Dijon); Dominique Dubois (Foix); Marie Paule Bonceour Martel (Limoges); François Cotton (Lyon); Alain Bonafé (Montpellier); Stéphane Chanalet (Nice); Françoise Hugon (Tarbes); Fabrice Bonneville, Christophe Cognard, François Chollet (Toulouse).

PET scans group: Pierre Payoux, Thierry Voisin, Julien Delrieu, Sophie Peiffer, Anne Hitzel, (Toulouse); Michèle Allard (Bordeaux); Michel Zanca (Montpellier); Jacques Monteil (Limoges); Jacques Darcourt (Nice).

Medical economics group: Laurent Molinier, Hélène Derumeaux, Nadège Costa (Toulouse). Biological sample collection: Bertrand Perret, Claire Vinel, Sylvie Caspar-Bauguil (Toulouse). Safety management: Pascale Olivier-Abbal

\section{Appendix A.2. DSA Group}

DSA Group: Sandrine Andrieu, Christelle Cantet, Nicola Coley

\section{References}

1. Mekonnen, A.B.; Redley, B.; de Courten, B.; Manias, E. Potentially Inappropriate Prescribing and Its Associations with HealthRelated and System-Related Outcomes in Hospitalised Older Adults: A Systematic Review and Meta-Analysis. Br. J. Clin. Pharmacol. 2021, 87, 4150-4172. [CrossRef]

2. Hanlon, J.T.; Schmader, K.E.; Samsa, G.P.; Weinberger, M.; Uttech, K.M.; Lewis, I.K.; Cohen, H.J.; Feussner, J.R. A Method for Assessing Drug Therapy Appropriateness. J. Clin. Epidemiol. 1992, 45, 1045-1051. [CrossRef]

3. Renom-Guiteras, A.; Meyer, G.; Thürmann, P.A. The EU(7)-PIM List: A List of Potentially Inappropriate Medications for Older People Consented by Experts from Seven European Countries. Eur. J. Clin. Pharmacol. 2015, 71, 861-875. [CrossRef] [PubMed]

4. O'Mahony, D.; O'Sullivan, D.; Byrne, S.; O'Connor, M.N.; Ryan, C.; Gallagher, P. STOPP/START Criteria for Potentially Inappropriate Prescribing in Older People: Version 2. Age Ageing 2015, 44, 213-218. [CrossRef] [PubMed]

5. Motter, F.R.; Fritzen, J.S.; Hilmer, S.N.; Paniz, É.V.; Paniz, V.M.V. Potentially Inappropriate Medication in the Elderly: A Systematic Review of Validated Explicit Criteria. Eur. J. Clin. Pharmacol. 2018, 74, 679-700. [CrossRef] [PubMed]

6. Beers, M.H.; Ouslander, J.G.; Rollingher, I.; Reuben, D.B.; Brooks, J.; Beck, J.C. Explicit Criteria for Determining Inappropriate Medication Use in Nursing Home Residents. UCLA Division of Geriatric Medicine. Arch. Intern. Med. 1991, 151, $1825-1832$. [CrossRef]

7. Grina, D.; Briedis, V. The Use of Potentially Inappropriate Medications among the Lithuanian Elderly According to Beers and EU(7)-PIM List-A Nationwide Cross-Sectional Study on Reimbursement Claims Data. J. Clin. Pharm. Ther. 2017, 42, 195-200. [CrossRef]

8. Anrys, P.; Boland, B.; Degryse, J.-M.; De Lepeleire, J.; Petrovic, M.; Marien, S.; Dalleur, O.; Strauven, G.; Foulon, V.; Spinewine, A. STOPP/START Version 2-Development of Software Applications: Easier Said than Done? Age Ageing 2016, 45, 590-593. [CrossRef]

9. Fralick, M.; Bartsch, E.; Ritchie, C.S.; Sacks, C.A. Estimating the Use of Potentially Inappropriate Medications Among Older Adults in the United States. J. Am. Geriatr. Soc. 2020, 68, 2927-2930. [CrossRef] 
10. Selke Krulichová, I.; Selke, G.W.; Thürmann, P.A. Trends and Patterns in EU(7)-PIM Prescribing to Elderly Patients in Germany. Eur. J. Clin. Pharmacol. 2021, 77, 1553-1561. [CrossRef]

11. Nauta, K.J.; Groenhof, F.; Schuling, J.; Hugtenburg, J.G.; van Hout, H.P.J.; Haaijer-Ruskamp, F.M.; Denig, P. Application of the STOPP/START Criteria to a Medical Record Database. Pharmacoepidemiol. Drug Saf. 2017, 26, 1242-1247. [CrossRef] [PubMed]

12. Anrys, P.; Strauven, G.; Boland, B.; Dalleur, O.; Declercq, A.; Degryse, J.-M.; De Lepeleire, J.; Henrard, S.; Lacour, V.; Simoens, S.; et al. Collaborative Approach to Optimise MEdication Use for Older People in Nursing Homes (COME-ON): Study Protocol of a Cluster Controlled Trial. Implement. Sci. 2016, 11, 35. [CrossRef]

13. Katz, S.; Ford, A.B.; Moskowitz, R.W.; Jackson, B.A.; Jaffe, M.W. Studies of Illness in the Aged: The Index of ADL: A Standardized Measure of Biological and Psychosocial Function. JAMA 1963, 185, 914-919. [CrossRef]

14. Andrieu, S.; Guyonnet, S.; Coley, N.; Cantet, C.; Bonnefoy, M.; Bordes, S.; Bories, L.; Cufi, M.-N.; Dantoine, T.; Dartigues, J.-F.; et al. Effect of Long-Term Omega 3 Polyunsaturated Fatty Acid Supplementation with or without Multidomain Intervention on Cognitive Function in Elderly Adults with Memory Complaints (MAPT): A Randomised, Placebo-Controlled Trial. Lancet Neurol. 2017, 16, 377-389. [CrossRef]

15. Charlson, M.E.; Pompei, P.; Ales, K.L.; MacKenzie, C.R. A New Method of Classifying Prognostic Comorbidity in Longitudinal Studies: Development and Validation. J. Chronic Dis. 1987, 40, 373-383. [CrossRef]

16. Fried, L.P.; Tangen, C.M.; Walston, J.; Newman, A.B.; Hirsch, C.; Gottdiener, J.; Seeman, T.; Tracy, R.; Kop, W.J.; Burke, G.; et al. Frailty in Older Adults: Evidence for a Phenotype. J. Gerontol. A Biol. Sci. Med. Sci. 2001, 56, M146-M156. [CrossRef] [PubMed]

17. Sheikh, J.I.; Yesavage, J.A. Geriatric Depression Scale (GDS): Recent Evidence and Development of a Shorter Version. Clin. Gerontol. J. Aging Ment. Health 1986, 5, 165-173. [CrossRef]

18. French High Authority for Health/Haute Autorité de Santé (HAS). Alert and Mastering of Drug Latrogenicity Indicators/Alerte Maîtrise Latrogénie (AMI); HAS: Paris, France, 2019.

19. Lang, P.O.; Dramé, M.; Guignard, B.; Mahmoudi, R.; Payot, I.; Latour, J.; Schmitt, E.; Pepersack, T.; Vogt-Ferrier, N.; Hasso, Y.; et al. Les Critères STOPP/START.v2 : Adaptation En Langue Française / STOPP/START.v2 Criteria: Adaptation into French Language. NPG Neurol.-Psychiatr.-Gériatrie 2015, 15, 323-336. [CrossRef]

20. Schafer, J.L. Multiple Imputation: A Primer. Stat. Methods Med. Res. 1999, 8, 3-15. [CrossRef] [PubMed]

21. Tommelein, E.; Mehuys, E.; Petrovic, M.; Somers, A.; Colin, P.; Boussery, K. Potentially Inappropriate Prescribing in CommunityDwelling Older People across Europe: A Systematic Literature Review. Eur. J. Clin. Pharmacol. 2015, 71, 1415-1427. [CrossRef] [PubMed]

22. Muhlack, D.C.; Hoppe, L.K.; Saum, K.-U.; Haefeli, W.E.; Brenner, H.; Schöttker, B. Investigation of a Possible Association of Potentially Inappropriate Medication for Older Adults and Frailty in a Prospective Cohort Study from Germany. Age Ageing 2020, 49, 20-25. [CrossRef] [PubMed]

23. Gnjidic, D.; Hilmer, S.N.; Blyth, F.M.; Naganathan, V.; Waite, L.; Seibel, M.J.; McLachlan, A.J.; Cumming, R.G.; Handelsman, D.J.; Le Couteur, D.G. Polypharmacy Cutoff and Outcomes: Five or More Medicines Were Used to Identify Community-Dwelling Older Men at Risk of Different Adverse Outcomes. J. Clin. Epidemiol. 2012, 65, 989-995. [CrossRef] [PubMed]

24. Allison, P.D. Logistic Regression Using SAS: Theory and Application, 2nd ed.; SAS Institute Inc.: Cary, NC, USA, 2012.

25. Galvin, R.; Moriarty, F.; Cousins, G.; Cahir, C.; Motterlini, N.; Bradley, M.; Hughes, C.M.; Bennett, K.; Smith, S.M.; Fahey, T.; et al. Prevalence of Potentially Inappropriate Prescribing and Prescribing Omissions in Older Irish Adults: Findings from The Irish LongituDinal Study on Ageing Study (TILDA). Eur. J. Clin. Pharmacol. 2014, 70, 599-606. [CrossRef] [PubMed]

26. Pérez, T.; Moriarty, F.; Wallace, E.; McDowell, R.; Redmond, P.; Fahey, T. Prevalence of Potentially Inappropriate Prescribing in Older People in Primary Care and Its Association with Hospital Admission: Longitudinal Study. BMJ 2018, 363, k4524. [CrossRef]

27. Wauters, M.; Elseviers, M.; Vaes, B.; Degryse, J.; Vander Stichele, R.; Christiaens, T.; Azermai, M. Mortality, Hospitalisation, Institutionalisation in Community-Dwelling Oldest Old: The Impact of Medication. Arch. Gerontol. Geriatr. 2016, 65, 9-16. [CrossRef] [PubMed]

28. Gallagher, P.F.; O'Connor, M.N.; O'Mahony, D. Prevention of Potentially Inappropriate Prescribing for Elderly Patients: A Randomized Controlled Trial Using STOPP/START Criteria. Clin. Pharmacol. Ther. 2011, 89, 845-854. [CrossRef] [PubMed] 